\title{
Determination of Wireless Communication Links Optimal Transmission Range Using Improved Bisection Algorithm
}

\author{
Enyenihi Henry Johnson ${ }^{1}$, Simeon Ozuomba ${ }^{2, *}$, Ifiok Okon Asuquo ${ }^{2}$ \\ ${ }^{1}$ Department of Electrical/Electronic Engineering, Akwa Ibom State University, Nigeria \\ ${ }^{2}$ Department of Electrical/Electronic and Computer Engineering, University of Uyo, Nigeria
}

Copyright $\bigcirc 2019$ by authors, all rights reserved. Authors agree that this article remains permanently open access under the terms of the Creative Commons Attribution License 4.0 International License

\begin{abstract}
In this paper, an improved bisection algorithm for computing the optimal transmission range of wireless communication links was presented. The optimal path length is based on the link budget equation for line-of-sight wireless communication links. Specifically, free space path loss model was used for the clear-air path loss while multipath fading and rain fading were the two fade mechanisms considered in the determination of the expected fade margin. Sample numerical example was carried out for a frequency of $10 \mathrm{GHz}$ and a site located in the International Telecommunication Union (ITU) rain zone $\mathrm{N}$. The result showed that at $10 \mathrm{GHz}$ and with the given network and link parameters, the improved bisection algorithm converged at the 7 th cycle while the classical bisection method converged at the 12th cycle. Further numerical examples were examined for frequencies ranging from $10 \mathrm{GHz}$ to $200 \mathrm{GHz}$. In all, the improved bisection method had at least $41 \%$ reduction in the convergence cycle when compared with that of the classical bisection method. A similar study with the classical Newton-Raphson method converged at the 4th cycle for a $12 \mathrm{GHz}$ signal while the improved bisection method converged at the 6th cycle. Essentially, the Newton-Raphson method converges faster than the bisection and the improved bisection methods. However, it is very difficult to apply the classical Newton-Raphson method when several clear-air path losses are to be considered or when complex path loss model such as the Hata model is used in the path loss computation. As such, the improved bisection method is preferred due to its simplicity and also it offers convergence performance that is comparable to that of the classical Newton-Raphson method.
\end{abstract}

Keywords Bisection Method, Adjustment Value for Iteration Variable, Line-of-sight Links, Rain Fade Depth, Multipath Fade Depth

\section{Introduction}

Today, there are several numerical iteration methods for solving non-linear equations $[1,2,3,4,5]$. Among the numerical iteration methods, the Newton-Raphson method and the bisection method are the most popular $[6,7,8,9]$. However, the two methods in their original forms have been associated with some shortcomings. The classical Newton-Raphson method requires some extra mathematical processes that make it difficult to be applied in many cases $[10,11,12,13]$. On the other hand, the classical bisection method is quite simple; however, when compared to the other methods, the bisection method takes longer time to converge $[14,15,16,17,18]$. Consequently, variants of the classical Newton-Raphson method and bisection method have been developed.

In this paper, the focus is on the application of improved bisection method in the computation of the optimal transmission range (path length) of wireless communication links [19]. Existing study employed the classical Newton-Raphson method [27]. Generally, the Newton-Raphson method converges faster than the bisection method and its modified versions. However, in order to apply the Newton-Raphson method in the determination of the optimal transmission range of wireless network, mathematical expression for the path length must first be derived and then the first derivative of such expression will also be derived. This approach becomes very difficult when different kinds of path losses are considered in the wireless network. Consequently, a simpler approach that does not require the derivation of complex mathematical expression and its derivative is proposed in this paper. Particularly, a modified bisection method is proposed which takes advantage of the simplicity of the bisection method but gives better 
convergence performance than the classical bisection method.

Notably, in the line-of-sight (LOS) wireless communication links, the maximum transmission range is always required to determine the maximum distance between the transmitter and the receiver. At the maximum transmission range, it is expected that the network will still meet the performance requirements $[20,21,22,23,24,25$, 26]. However, a recent study proposed optimal transmission range at which point the available fade margin in the link can accommodate the maximum fade depth that can occur in the link based on the design specifications. Although such optimal length computation has been done using the classical Newton-Raphson method [27], in this paper, the modified bisection method is presented due to its simplicity and comparable convergence performance with the Newton-Raphson method.

The study is carried out in Imo state, Nigeria where multipath fading and rain fading are the two major fade mechanisms mostly considered in wireless network design. Furthermore, mutual exclusive relationship exists among multipath fading, and rain fading [28]. As such, in practice, the fade mechanism with higher fade depth is considered as the effective fade mechanism for the communication link. In addition, in locations where only multipath and rain fade mechanisms are considered, for frequencies above $10 \mathrm{GHz}$, rain fading dominates whereas; the multipath fading dominates at the lower frequencies [29,30,31]. In addition, according to [27], when multipath fading dominates, the optimal path length can be determined using a close-form solution. However, when rain fading dominates, the resulting mathematical expression leads to a product log function that does not have a closed-form solution. As such, a numerical method or the Lambert $\mathrm{W}$ function approach can be used to determine the optimal path length [27]. In this paper, a modified bisection numerical method is used. The study focused on the frequencies above $10 \mathrm{GHz}$ where the rain fading is the dominant fade mechanism for the case study area.

In all, the main motive for the study is to derive a simple numerical iteration method that can be used to determine the optimal path length in the tropical regions where rain fading and multipath fading are the prevailing fade mechanisms. Presently, available studies on the optimal path length focused on free space path loss as the only loss the signal will experience along with the rain or multipath fading. However, there are other complex path loss models and also additional path losses due to diffraction effect of obstructions in the signal path. When such complex path losses models and diffraction path loss are considered, it will become extremely difficult to use the classical Newton-Raphson method. As such, a simpler numerical iteration method, like the improved bisection method is needed since it can also give good convergence performance comparable to that of the classical Newton-Raphson method.

\section{Determination of Maximum Transmission Range for Line-of-sight (Los) Wireless Communication Links}

The received signal strength, $\mathrm{P}_{\mathrm{R}}$ of LOS link is given as follows [20]:

$$
\mathrm{P}_{\mathrm{R}}=f m_{s}+P_{S}=\mathrm{P}_{\mathrm{T}}+\left(\mathrm{G}_{\mathrm{T}}+\mathrm{G}_{\mathrm{R}}\right)-\mathrm{LFSP}
$$

Where:

fms $=$ fade margin $(\mathrm{dBm})$

$P_{S}=$ receiver sensitivity $(\mathrm{dBm})$

$P_{R}=$ Received Signal Power $(\mathrm{dBm})$

$\mathrm{P}_{\mathrm{T}}=$ Transmitter Power Output $(\mathrm{dBm})$

$\mathrm{G}_{\mathrm{T}}=$ Transmitter Antenna Gain (dBi)

$\mathrm{G}_{\mathrm{R}}=$ Receiver Antenna Gain (dBi)

LFSP $=$ Free Space Path Loss $(\mathrm{dB})$.

If the frequency, $\mathrm{f}$ is in $\mathrm{GHz}$ and $\mathrm{d}$ is given in $\mathrm{km}$, then, LFSP is given as;

$$
\text { LFSP }=32.4+20 \log \left(f^{*} 1000\right)+20 \log (d)
$$

The transmission range (d) can be determined from Equations 1 to 2 as follows:

$$
\mathrm{d}=10\left(\frac{\left(\mathrm{P}_{\mathrm{T}}+\mathrm{G}_{\mathrm{T}}+\mathrm{G}_{\mathrm{R}}-f m_{S}-P_{S}\right)-32.4-20 \log (\mathrm{f} * 1000)}{20}\right)
$$

The fade depth $A_{\text {multipath }}(\mathrm{dB})$ can be determined from the ITU multipath fading model for quick planning applications which is expressed as [27];

$$
p o=\mathrm{Kd}^{3.1}\left(1+\left|\varepsilon_{\mathrm{P}}\right|\right)^{-1.29} \quad\left(f^{0.8}\right) 10^{\left(-0.00089 h_{L^{-}}-\frac{\left(A_{\text {multipath }}\right)}{\mathbf{1 0}}\right)}
$$

Where:

$P o$ is the percentage of time that $\boldsymbol{A}_{\text {multipath }}$ is exceeded in the average worst month

$\mathrm{d}$ is the propagation transmission range or distance (in $\mathrm{km}$ ) between the transmitter and the receiver

$f$ is frequency $(\mathrm{GHz})$

$h_{L}$ is altitude of lower antenna $(\mathrm{m})$

$A_{\text {multipath }}$ is multipath fade depth (dB)

$d N 1$ is point refractivity gradient

$\mathrm{K}$ is geoklimatic factor and can be obtained from:

$$
K=10^{(-4.6-0.0027 d N 1)}
$$

$\varepsilon_{\mathrm{P}}$ is the path inclination, (in mrad). $\varepsilon_{\mathrm{P}}$ is calculated using the following expression

$$
\left|\varepsilon_{p}\right|=\frac{\left(\left|h_{t}-h_{r}\right|\right)}{d}
$$

where:

$\mathrm{d}$ is the propagation transmission range or distance (in $\mathrm{km}$ ) between the transmitter and the receiver

$h_{t}$ is the antenna transmitter antenna height

$h_{r}$ is the receiver transmitter antenna height (where $h_{t}$ and $h_{r}$ are in meters about sea level) : 


$$
h_{L}=\operatorname{minimum}\left(h_{t}, h_{r}\right)
$$

Hence, the multipath fade depth, $\boldsymbol{A}_{\text {multipath }}$ (in dB) is obtained from the expression for Po as follows;

$$
\boldsymbol{A}_{\text {multipath }}=10\left(-0.00089 h_{L}\right)-(10) \log \left(\frac{p o}{\left\{K\left(d^{3.1}\right)\left(1+\left|\varepsilon_{p}\right|\right)^{-1.29}\left(f^{0.8}\right)\right\}}\right)
$$

The ITU-R PN.838 recommendations specified the specific attenuation originating from rainfall as $\gamma_{\mathrm{R}_{\mathrm{po}}}$ in $\mathrm{dB} / \mathrm{km}$ and modeled it using the power-law relationship as follows [27] ;

$$
\gamma_{R_{p o}}=k\left(R_{p o}\right)^{\alpha}
$$

Where $R_{p o}$ is the rainfall rate in $\mathrm{mm} / \mathrm{h}$ exceeded for $P o \%$ of an average year (or stated another way, $R_{p o}$ is the rainfall rate in $\mathrm{mm} / \mathrm{h}$ for a particular link percentage outage, Po). $\mathrm{k}$ and $\alpha$ are frequency dependent. The rain fade depth, $A_{\text {Rain }}$ for a transmission range, $\mathrm{d}$ (in $\mathrm{Km}$ ) is given as

$$
A_{\text {Rain }}=\left(\gamma_{R_{p o}}\right) d=\left(k\left(R_{p o}\right)^{\alpha}\right) d
$$

In reality, $\mathrm{k}$ and $\alpha$ are given for the vertical polarization and horizontal polarization and hence, $A_{\text {Rain }}$ is computed for vertical polarization and horizontal polarization and the larger of the two is the effective rain fade depth.

In all, the larger of the rain fade depth and multipath fade depth is taken as the link maximum fade depth $\left(f d_{m}\right)$ and it is expressed as;

$$
f d_{m}=\operatorname{maximum}\left(\boldsymbol{A}_{\text {multipath }}, A_{\text {Rain }}\right)
$$

The optimal transmission range $\left(\mathrm{d}_{\text {mop }}\right)$ is obtained when the following condition is fulfilled;

$$
f d_{m}=P_{R}-P_{S}
$$

\section{Development of the Improved Bisection Algorithm for the Determination of Optimal Transmission Range}

\subsection{Theory of the Improved Bisection Method for the Determination of Optimal Transmission Range}

The bisection method is a binary search method that is used to find the root of an equation, such as function $\mathrm{f}(\mathrm{x})$ in a given interval, where the root is the value of ' $x$ ' for which $f(x)=0$. The bisection method is based on the intermediate value theorem which states that if $\mathrm{f}(\mathrm{x})$ is a continuous function and there are two real numbers a and $\mathrm{b}$ such that $\mathrm{f}(\mathrm{a}) * \mathrm{f}(\mathrm{b})$ 0 and $\mathrm{f}(\mathrm{b})<0$ ), then it is guaranteed that it has at least one root between them. Given that $\mathrm{X}_{u p}=b, \mathrm{X}_{L w}=a$ and $\mathrm{X}_{\text {new }}=c$ the bisection method can be stated as follows;

$$
\begin{aligned}
& \mathrm{X}_{\text {new }}=\left(\frac{\mathrm{X}_{u p}-\mathrm{X}_{L w}}{2}\right) \\
& \mathrm{X}_{\text {new }}=\left(\frac{\mathrm{X}_{u p}-\mathrm{X}_{L w}}{\beta}\right)
\end{aligned}
$$

Steps for performing the bisection method are as follows:

1. Set or initialize the error tolerance, $\epsilon_{s}$

2. Find middle point $\mathrm{X}_{\text {new }}=\left(\frac{\mathrm{X}_{u p}-\mathrm{X}_{L w}}{2}\right)$

3. If $\mathrm{f}\left(\mathrm{X}_{\text {new }}\right)=0$ or $\mathrm{f}\left(\mathrm{X}_{\text {new }}\right)<\epsilon_{s}$ then Stop // $\mathrm{X}_{\text {new }}$ is the root of the solution.

4. Else If value $\left.\mathrm{f}\left(\mathrm{X}_{L w}\right) * \mathrm{f}\left(\mathrm{X}_{\text {new }}\right)\right)<0$ then

$\mathrm{X}_{\text {up }}=\mathrm{X}_{\text {new }} / /$ root lies between $\mathrm{X}_{L w}$ and $\mathrm{X}_{\text {new }}$.go to step $1 / /$ recur for $\mathrm{X}_{L w}$ and $\mathrm{X}_{\text {new }}$

5. Else If $\mathrm{f}\left(\mathrm{X}_{\text {up }}\right) * \mathrm{f}\left(\mathrm{X}_{\text {new }}\right)<0$ then

$\mathrm{X}_{L w}=\mathrm{X}_{\text {new }} / /$ root lies between $\mathrm{X}_{\text {new }}$ and $\mathrm{X}_{\text {up }}$ go to step $1 / /$ recur for $\mathrm{X}_{\text {new }}$ and $\mathrm{X}_{\text {up }}$

6. Else Stop // given function does not follow one of the assumptions.

\subsection{The Improved Bisection Algorithm for the Determination of the Optimal Transmission Range of Line-of-sight Wireless Communication Links}

The new root of the function based on bisection method can be stated as follows; 


$$
\mathrm{X}_{\text {new }}=\left(\frac{\mathrm{X}_{u p}-\mathrm{X}_{L w}}{\beta}\right)
$$

For the classic bisection method $\beta=2$, hence

$$
\mathrm{X}_{\text {new }}=\left(\frac{\mathrm{X}_{u p}-\mathrm{X}_{L w}}{\beta}\right)=\frac{\mathrm{X}_{u p}-\mathrm{X}_{L w}}{2}
$$

Although, bisection method uses $\beta=2$ with little knowledge of the prevailing link parameters, the $\beta$ factor can be improved to suit the link operating conditions. In this research, $\beta$ is defined as;

$$
\beta=\left|\frac{\mathrm{X}_{u p}}{\mathrm{X}_{u p}-\mathrm{X}_{L w}}\right|
$$

Consider a numerical example where $\mathrm{X}_{L w}=16$ and $\mathrm{X}_{u p}=102$ then

$$
\beta=\left|\frac{\mathrm{X}_{u p}}{\mathrm{X}_{u p}-\mathrm{X}_{L w}}\right|=\left|\frac{102}{102-16}\right|=1.186
$$

Hence,

$$
\mathrm{X}_{\text {new }}=\left(\frac{\mathrm{X}_{u p}-\mathrm{X}_{L w}}{\beta}\right)=\left(\frac{102-16}{1.186}\right)=72.513
$$

For the classical bisection method with $\beta=2$ the value of $\mathrm{X}_{\text {new }}$ will be

$$
\mathrm{X}_{\text {new }}=\left(\frac{102-16}{2}\right)=143
$$

As can be seen, whereas the bisection method will use $\beta=2$, the improved bisection method will use $\beta=1.186$. The adjusted value of $\beta$ is expected to give rise to faster convergence of the algorithm. As regards the optimal transmission range of the microwave links, the bisection method uses $\beta=2$ because it has little knowledge of the prevailing link parameters. In this paper, given that the fade margin at design time specification is denoted as $f m_{s}$ and the corresponding fade depth is denoted as $f d_{m}$, then; $f m e=f m_{s}$ and $\beta=\left|\frac{f d_{m}}{f d_{m}-f m e}\right|$. Now consider a numerical example, if $f m e=$ $f m_{s}=19.96 \mathrm{~dB}$ and $f d_{m}=124.83 \mathrm{~dB}$ then;

$$
\beta=\left|\frac{f d_{m}}{f d_{m}-f m e}\right|=\left|\frac{124.83}{124.83-19.96}\right|=\frac{124.83}{104.87}=1.1903
$$

As can be seen, whereas the bisection method will use $\beta=2$, the improved bisection method will use $\beta=1.1903$. The improved $\beta$ value is expected to give rise to faster convergence of the algorithm. The algorithm for the improved bisection method is the same as the classical bisection method present in this chapter except that in the improved bisection method the value of $\beta$ must be computed first and used in the iteration.

$$
\beta=\left|\frac{f d_{m}}{f d_{m}-f m e}\right|
$$

The algorithm for the improved bisection method for optimal transmission range is given as follows;

\section{Step 1: Specify requisite link parameters values}

Specify the following parameters

(i) $P_{S}=$ the receiver sensitivity in $\mathrm{dB}$

(ii) $\mathrm{fm}_{s}$ the specified (required) fade margin in $\mathrm{dB}$

(iii) $\mathrm{PT}=$ the transmitter power output $(\mathrm{dBm})$

(iv) $\mathrm{GT}=$ the transmitter antenna gain $(\mathrm{dBi})$

(v) $\mathrm{GR}=$ the receiver antenna gain $(\mathrm{dBi})$

(vi) $\mathrm{LT}=$ the losses from transmitter (cable, connectors etc.) $(\mathrm{dB})$

(vii) $\mathrm{LR}=$ the losses from receiver (cable, connectors etc.) $(\mathrm{dB})$

(viii) $\mathrm{LM}=$ the miscellaneous losses (fade margin, polarization misalignment etc.) (dB)

(ix) Specified relative error tolerance, $\epsilon_{s}$ where $\epsilon_{s}=0.01 \%=\frac{0.01}{100}=0.0001$

\section{Step 2: Initialize the parameters}

Step 2.1 Set k $=0$; where $\mathrm{k}$ represent the iteration counter

Step $2.2 \mathrm{fme}_{(k)}=\mathrm{fm}_{s}$ 
Step $2.3 \in_{s}=0.01 \%$

Step $2.4 j=0 / / \mathrm{j}$ is iteration counter

Step 3 Compute the operating free space path loss, $L_{\mathrm{FSP}}$ and set the initial operating free space path loss, $\mathrm{L}_{\mathrm{FSP}(\mathrm{k})}$

\section{Step 3.1}

Compute $P_{R}$, the received signal power in $\mathrm{dB}$ as follows;

$$
P_{R}=f m e_{(k)}+P_{S}
$$

\section{Step 3.2}

Compute LFSP, the Free Space Path Loss (dB) as follows;

$$
\mathrm{LFSP}=\mathrm{P}_{\mathrm{T}}+\mathrm{G}_{\mathrm{T}}+\mathrm{G}_{\mathrm{R}}-\mathrm{P}_{\mathrm{R}}=\mathrm{P}_{\mathrm{T}}+\mathrm{G}_{\mathrm{T}}+\mathrm{G}_{\mathrm{R}}-f m e_{(k)}-P_{S}
$$

\section{Step 3.3}

Set the initial operating free space path loss, $\mathbf{L}_{\mathbf{F S P}(\mathbf{0})}$

$$
\mathrm{L}_{\mathrm{FSPe}(\mathrm{k})}=\mathrm{L}_{\mathrm{FSP}}
$$

\section{Step 3.4}

Compute the operating fade depth, $\boldsymbol{f} \boldsymbol{d}_{\boldsymbol{m}}$ and set the initial effective operating fade margin, $f d_{m e(k)}$

\section{Step 3.5}

Compute d, the length of the link in km as follows;

$$
\mathrm{d}=10^{\left(\frac{\mathrm{L}_{\mathrm{FSP}(\mathrm{k})}-32.4-20 \log (\mathrm{f} * 1000)}{20}\right)}=10^{\left(\frac{\left(\mathrm{P}_{\mathrm{T}}+\mathrm{G}_{\mathrm{T}}+\mathrm{G}_{\mathrm{R}}-\mathrm{P}_{\mathrm{R}}\right)-32.4-20 \log (\mathrm{f} * 1000)}{20}\right)}
$$

\section{Step 3.6}

Compute $A_{\text {Rain }}$, the operating rain fade depth in $\mathrm{dB}$ as follows;

$$
\begin{aligned}
& \left.A_{R(h)}=\left(\left\langle\gamma_{\mathrm{R}_{\mathrm{po}}}\right\rangle_{\mathrm{h}}\right) \mathrm{d}=\left(\mathrm{K}_{\mathrm{h}}\left(\mathrm{R}_{\mathrm{po}}\right)^{\alpha_{\mathrm{h}}}\right) \mathrm{d}\right\} \\
& \left.A_{R(v)}=\left(\left\langle\gamma_{\mathrm{R}_{\mathrm{po}}}\right\rangle_{\mathrm{v}}\right) \mathrm{d}=\left(\mathrm{K}_{\mathrm{v}}\left(\mathrm{R}_{\mathrm{po}}\right)^{\alpha_{\mathrm{v}}}\right) \mathrm{d}\right\} \\
& A_{\text {Rain }}=\max \left(\left(\mathrm{K}_{\mathrm{v}}\left(\mathrm{R}_{\mathrm{po}}\right)^{\alpha_{\mathrm{v}}}\right) *\left(\mathrm{~K}_{\mathrm{h}}\left(\mathrm{R}_{\mathrm{po}}\right)^{\alpha_{\mathrm{h}}}\right) * \mathrm{~d}\right)=\max \left(A_{R(h)}, A_{R(v)}\right) \mathrm{d} \\
& A_{\text {Rain }(j)}=A_{\text {Rain }}
\end{aligned}
$$

\section{Step 3.7}

Compute the operating multipath fade depth, $\boldsymbol{A}_{\text {multipath }}$ in dB as follows;

$$
\boldsymbol{A}_{\text {multipath }}=10\left(-0.00089 h_{L}\right)-(10) \log \left(\frac{p o}{\left\{K\left(d^{3.1}\right)\left(1+\left|\varepsilon_{p}\right|\right)^{-1.29}\left(f^{0.8}\right)\right\}}\right)
$$

\section{Step 3.8}

Compute the operating fade depth, $f d_{m}$ in $\mathrm{dB}$ as follows;

$$
f d_{m}=\max \left(\boldsymbol{A}_{\text {multipath }}, A_{\text {Rain }}\right)=\max \left(\boldsymbol{A}_{\text {multipath }}\left(\max \left(A_{R(h)}, A_{R(v)}\right)\right)\right)
$$

\section{Step 3.9}

Set the initial effective operating fade margin, $f d_{m e(k)}$

$$
f d_{m e(k)}=f d_{m}
$$

Step 4

$$
\mathrm{K}=\mathrm{K}+1 \text { : Increase } \mathrm{k} \text { by } 1
$$

Step 5 Use the values of $f m e_{(k-1)}$ and $f d_{m e(k-1)}$ to determine the adjustment value where the adjustment value is denoted as $\Delta_{f m e(k)}$

Step 5.1 Set the two values $x_{l(k)}$ and $x_{u(k)}$ for fade margin where;

$$
x_{l(k)}=\operatorname{minimum}\left(f m e_{(k-1)}, f d_{m e(k-1)}\right)
$$




$$
x_{u(k)}=\operatorname{maximum}\left(f m e_{(k-1)}, f d_{m e(k-1)}\right)
$$

Step 5.2 Determine the adjustment value for $\mathrm{fm}_{(k-1)}$ where the adjustment value, $\Delta_{f m}$ is the a point between $x_{l(k)}$ and $x_{u(k)}$ obtain as follows;

$$
\begin{gathered}
\beta=\left|\frac{x_{u(k)}}{x_{u(k)}-x_{l(k)}}\right| \\
\Delta_{f m}=x_{m(k)}=\frac{x_{u(k)}-x_{l(k)}}{\beta} \\
\Delta_{f m(j)}=\Delta_{f m}
\end{gathered}
$$

Step 6 Determine the adjusted value for $f d_{m e(k)}$ where the adjustment value, $f d_{m e(k)}$ is given as;

$$
\begin{aligned}
& f d_{m e(k)}=f d_{m e(k-1)}+\Delta_{f m} \text { if } x_{l(k)}=f d_{m e(k-1)} \\
& f d_{m e(k)}=f d_{m e(k-1)}-\Delta_{f m} \text { if } x_{u(k)}=f d_{m e(k-1)}
\end{aligned}
$$

\section{Step 7}

Determine the adjusted value for optimal transmission range, $d_{e(k)}$ where the adjusted value is given as;

$$
\text { If }\left(A_{e R(h)} \geq A_{e R(v)}\right) \text { then }\left(\gamma_{\mathrm{R}_{\mathrm{po}}}=\left\langle\gamma_{\mathrm{R}_{\mathrm{po}}}\right\rangle_{\mathrm{h}}\right)
$$

otherwise $\left(\gamma_{\mathrm{R}_{\mathrm{po}}}=\left\langle\gamma_{\mathrm{R}_{\mathrm{po}}}\right\rangle_{\mathrm{v}}\right)$. Then

$$
d_{e(k)}=\frac{f d_{m e(k)}}{\gamma_{R_{p o}}}
$$

\section{Step 8}

Determine the adjusted value for effective free space path loss, $\mathrm{L}_{\mathrm{FSPe}(\mathrm{k})}$ where the adjustment value is given as;

$$
\mathrm{L}_{\mathrm{FSPe}(\mathrm{k})}=32.4+20 \log \left(\mathrm{f}^{*} 1000\right)+20 \log \left(d_{e(k)}\right)
$$

\section{Step 9}

Determine the adjusted value for effective fade margin where the adjusted value is given from as;

$$
f m_{e(\mathrm{k})}=\left(\mathrm{LFSP}+f m_{s}\right)-\mathrm{L}_{\mathrm{FSP}(\mathrm{k})}
$$

\section{Step 10}

Check if the optimal transmission range condition is met, that is if;

Step 10.1

Step 10.1.1

$$
\begin{aligned}
& \epsilon_{(k)}=\left|\frac{f d_{m e(k)}-f m_{e(\mathrm{k})}}{f d_{m e(k)}}\right| 100 \% \\
& =\left|\frac{f d_{m e(k)}-\left(\left(\mathrm{L}_{\mathrm{FSP}}+f m_{s}\right)-\mathrm{L}_{\mathrm{FSP}(\mathrm{k})}\right)}{f d_{m e(k)}}\right| 100 \%
\end{aligned}
$$

$$
\begin{array}{ll}
\text { Step 10.1.2 } & f m e_{(j)}=f m e_{(k)} \\
\text { Step 10.1.3 } & \mathrm{L}_{\mathrm{FSP}(\mathrm{j})}=\mathrm{L}_{\mathrm{FSPe}(\mathrm{k})} \\
\text { Step 10.1.4 } & f d_{m e(j)}=f d_{m e(k)} \\
\text { Step 10.1.5 } & \mathrm{d}_{\mathrm{e}(\mathrm{j})}=d_{e(k)}
\end{array}
$$

$$
\text { Step 10.1.6 } \quad \epsilon_{(j)}=\epsilon_{(k)}
$$

\section{Step 10.2}

$$
\begin{array}{r}
\text { If }\left(\epsilon_{(k)} \%>\left|\epsilon_{s} \%\right|\right) \text { Then } \\
\text { Goto Step } 4
\end{array}
$$

Else

Endif

$$
\text { Goto Step } 11
$$

\section{Step 11}

$\begin{array}{ll}\text { Step 11.1 } & f m e_{o p}=f m e_{(k)} \\ \text { Step 11.2 } & \mathrm{L}_{\mathrm{FSPop}}=\mathrm{L}_{\mathrm{FSPe}(\mathrm{k})} \\ \text { Step 11.3 } & f d_{\text {mop }}=f d_{m e(k)} \\ \text { Step 11.4 } & \mathrm{d}_{\text {mop }}=d_{e(k)} \\ \text { Step 11.5 } & \epsilon_{o p(j)}=\epsilon_{(k)}\end{array}$

Step 12 Stop

\section{Results and Discussions}

In the sample numerical computation which the results are shown in Table 1 and Table 2, as well as Figure 1 and Figure 2, the frequency is $10 \mathrm{GHz}$, the transmitter power is $12 \mathrm{~dB}$, the transmitter antenna gain is $30 \mathrm{dBi}$, the receiver antenna gain is $30 \mathrm{dBi}$, the receiver sensitivity is $-82 \mathrm{~dB}$, the fade margin is $18 \mathrm{~dB}$, the network percentage availability is $99.99 \%$, the ITU rain zone is $\mathrm{N}$ and hence the rain rate is $95 \mathrm{~mm} . \mathrm{hr}$, the rain fading constants are; $k_{\mathrm{h}}=$ $0.01217, a_{\mathrm{h}}=1.2571, k_{\mathrm{v}}=0.01129$ and $a_{\mathrm{v}}=1.2156$. The convergence cycle for the improved bisection method is 7. That means, as shown in Table 1 and Table 2 (as well as, Figure 1 and Figure 2), the improved bisection algorithm is iterated for 7 times before the optimal transmission range is obtained. Also, the optimal transmission range is $7.28226 \mathrm{~km}$, the optimal free space path loss is $129.69 \mathrm{~dB}$, the optimal fade margin the system can accommodate is $24.31 \mathrm{~dB}$ and the optimal fade depth value is $24.31 \mathrm{~dB}$. In essence, for the improved bisection algorithm, at the optimal transmission range, a maximum fade depth of $24.31 \mathrm{~dB}$ can be accommodated by the link which is the same with the optimal fade depth value of $24.31 \mathrm{~dB}$. It can be seen from Table 2 and Figure 2 that the initial fade margin specified for the system is $18 \mathrm{~dB}$. At this initial point, in Table 2 and Figure 2, the initial maximum transmission range is $15.1356 \mathrm{~km}$, the initial path loss is $136.04 \mathrm{~dB}$, and the initial fade depth is $50.54 \mathrm{~dB}$ while the initial received signal power is $-60.04 \mathrm{~dB}$. At the optimal point, the path maximum path loss has reduced by $6.35 \mathrm{~dB}$ to a value of $129.69 \mathrm{~dB}$ while the received signal power has increased the same value of $-60.04 \mathrm{~dB}$ to a value of -57.69 dB From Table 1 and Figure 1, it will be noticed that the rain fading is equal to the effective fade depth. In essence, for the given frequency, rain zone and percentage availability, the rain fading is greater than the multipath fading and hence, determines the effective fade depth that will be experienced in the link.

The effective path length versus number of iterations (n), 
as well as the percentage error with respect to the optimal path length for the improved bisection method and the classical bisection method is shown in Table 3 and Figure 3. The two models started with initial percentage error of -107.8415 but at the end of the first iteration ( $i=1)$ the improve bisection method recorded percentage error of
$-21.4781 \%$ whereas the classical bisection method recorded $-40.8525 \%$. In all, the improved bisection method converges faster than the classical bisection method. Consequently, the improved bisection method converged at the $7^{\text {th }}$ cycle $(i=7)$ whereas the classical bisection method converged at the $12^{\text {th }}$ cycle.

Table 1. Improved bisection method: how the key link parameters vary with number of iterations (n)

\begin{tabular}{|c|c|c|c|c|c|c|}
\hline $\begin{array}{c}\text { Number Of } \\
\text { Iterations (n) }\end{array}$ & $\begin{array}{c}\text { Effective Rain } \\
\text { Fading }\end{array}$ & $\begin{array}{c}\text { Free Space } \\
\text { Path Loss }\end{array}$ & $\begin{array}{c}\text { Multipath } \\
\text { Fading }\end{array}$ & $\begin{array}{c}\text { Effective Path } \\
\text { Length }\end{array}$ & $\begin{array}{c}\text { Effective Fade } \\
\text { Depth }\end{array}$ & $\begin{array}{c}\text { Effective Fade } \\
\text { Margin }\end{array}$ \\
\hline 0 & 50.54 & 136.04 & 21.29 & 15.13561 & 50.54 & 17.96 \\
\hline 1 & 29.54 & 131.38 & 12.01 & 8.84641 & 29.54 & 22.62 \\
\hline 2 & 25.08 & 129.95 & 9.11 & 7.51187 & 25.08 & 24.05 \\
\hline 3 & 24.41 & 129.72 & 8.63 & 7.31180 & 24.41 & 24.28 \\
\hline 4 & 24.33 & 129.69 & 8.57 & 7.28597 & 24.33 & 24.31 \\
\hline 5 & 24.32 & 129.69 & 8.56 & 7.28273 & 24.32 & 24.31 \\
\hline
\end{tabular}

Table 2. Improved bisection method and the classical bisection method: initial free space path loss, optimal values for free space path loss, fade depth, fade margin, path length and convergence cycle

\begin{tabular}{|c|c|c|c|c|c|c|}
\hline & $\mathbf{n}$ & $\begin{array}{c}\text { Free Space Path } \\
\text { Loss (in dB) }\end{array}$ & $\begin{array}{c}\text { Received Power } \\
\text { (in dBm) }\end{array}$ & $\begin{array}{c}\text { Fade Depth } \\
\text { (in dB) }\end{array}$ & $\begin{array}{c}\text { Path Length } \\
\text { (in km) }\end{array}$ & $\begin{array}{c}\text { Fade Margin } \\
\text { (in dB) }\end{array}$ \\
\hline Initial Value & $\mathbf{0}$ & 136.04 & -64.04 & 50.54 & 15.1356 & 18 \\
\hline $\begin{array}{c}\text { Optimal Value For The } \\
\text { Improved Bisection method }\end{array}$ & $\mathbf{7}$ & 129.69 & -57.69 & 24.31 & 7.2823 & 24.31 \\
\hline $\begin{array}{c}\text { Optimal Value For The } \\
\text { Classical Bisection method }\end{array}$ & $\mathbf{1 2}$ & 129.69 & -57.69 & 24.31 & 7.2823 & 24.31 \\
\hline
\end{tabular}

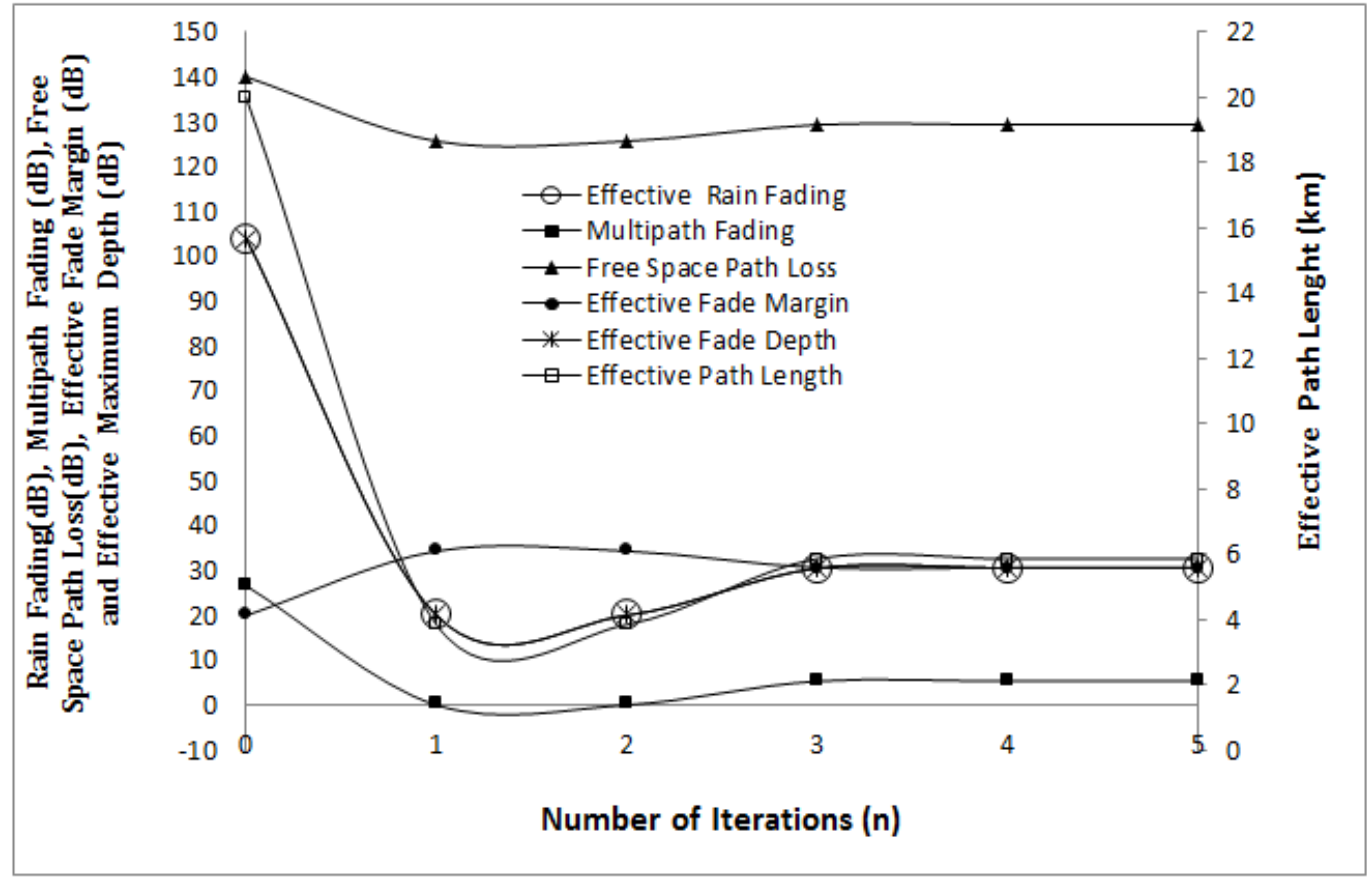

Figure 1. Improved bisection method: How the key link parameters vary with number of iterations (n) 


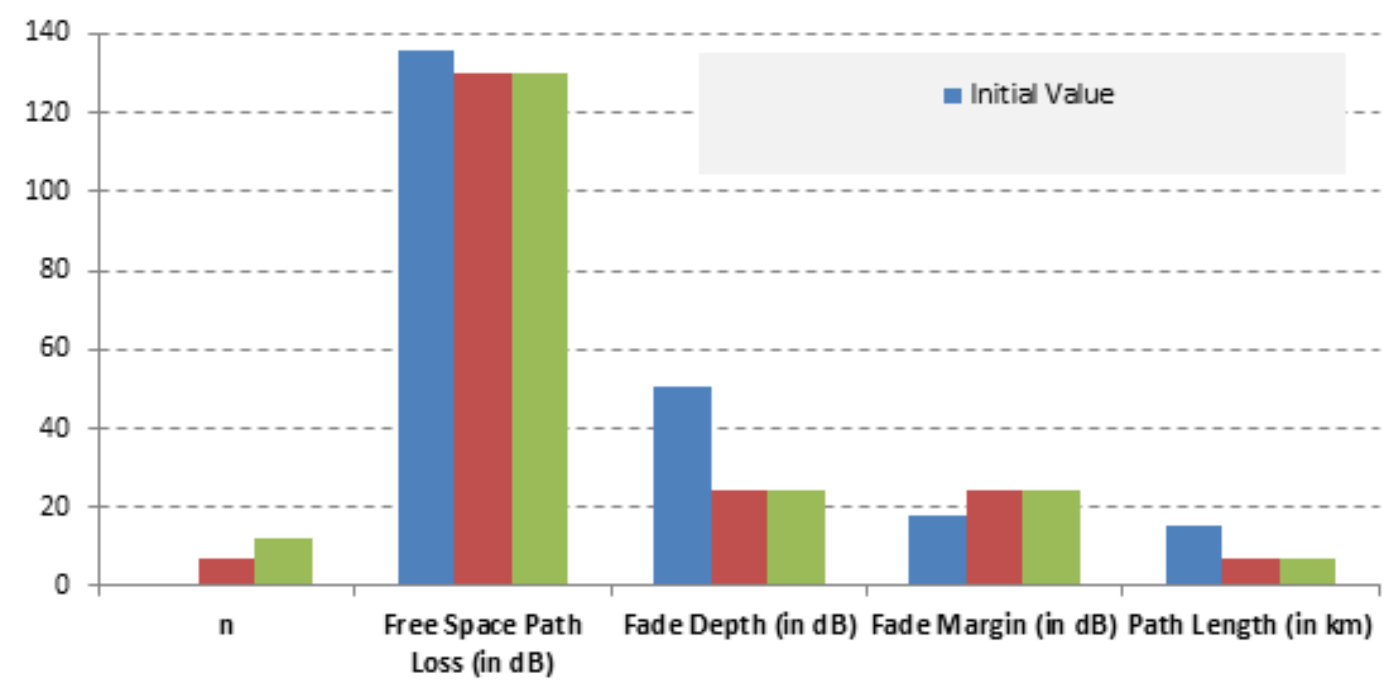

Figure 2. Improved bisection method and the classical bisection method: initial free space path loss, optimal values for free space path loss, fade depth, fade margin, path length and convergence cycle

Table 3. Improved bisection method and the classical bisection method: effective path length versus number of iterations (n)

\begin{tabular}{|c|c|c|c|c|}
\hline $\begin{array}{c}\text { Number Of } \\
\text { Iterations (i) }\end{array}$ & $\begin{array}{c}\text { Improved Bisection } \\
\text { method Effective Path } \\
\text { Length (Km) }\end{array}$ & $\begin{array}{c}\text { Classical Bisection } \\
\text { method Effective Path } \\
\text { Length (Km) }\end{array}$ & $\begin{array}{c}\text { Improved Bisection method: } \\
\text { Percentage Error With Respect } \\
\text { to the optimal path length }\end{array}$ & $\begin{array}{c}\text { Classical Bisection method: } \\
\text { Percentage Error With Respect } \\
\text { to the optimal path length }\end{array}$ \\
\hline 0 & 15.1356 & 15.1356 & -107.841 & -107.841 \\
\hline 1 & 8.8464 & 10.2573 & -21.4781 & -40.8525 \\
\hline 2 & 7.5119 & 8.3242 & -3.15285 & -14.3073 \\
\hline 3 & 7.3118 & 7.6293 & -0.40509 & -4.76498 \\
\hline 4 & 7.286 & 7.3952 & -0.05081 & -1.55033 \\
\hline 5 & 7.2827 & 7.3187 & -0.00549 & -0.49984 \\
\hline 6 & 7.2823 & 7.294 & 0 & -0.16066 \\
\hline 7 & 7.2823 & 7.286 & 0 & -0.05081 \\
\hline 8 & 7.2823 & 7.2835 & 0 & -0.01648 \\
\hline 9 & 7.2823 & 7.2827 & 0 & -0.00137 \\
\hline 10 & 7.2823 & 7.2824 & 0 & 0 \\
\hline 11 & 7.2823 & 7.2823 & 0 & 0 \\
\hline 12 & 7.2823 & 7.2823 & 0 & 0 \\
\hline 13 & 7.2823 & 7.2823 & 0 & 0 \\
\hline 14 & 7.2823 & 7.2823 & 0 & 0 \\
\hline 15 & 7.2823 & 7.2823 & & 0 \\
\hline
\end{tabular}




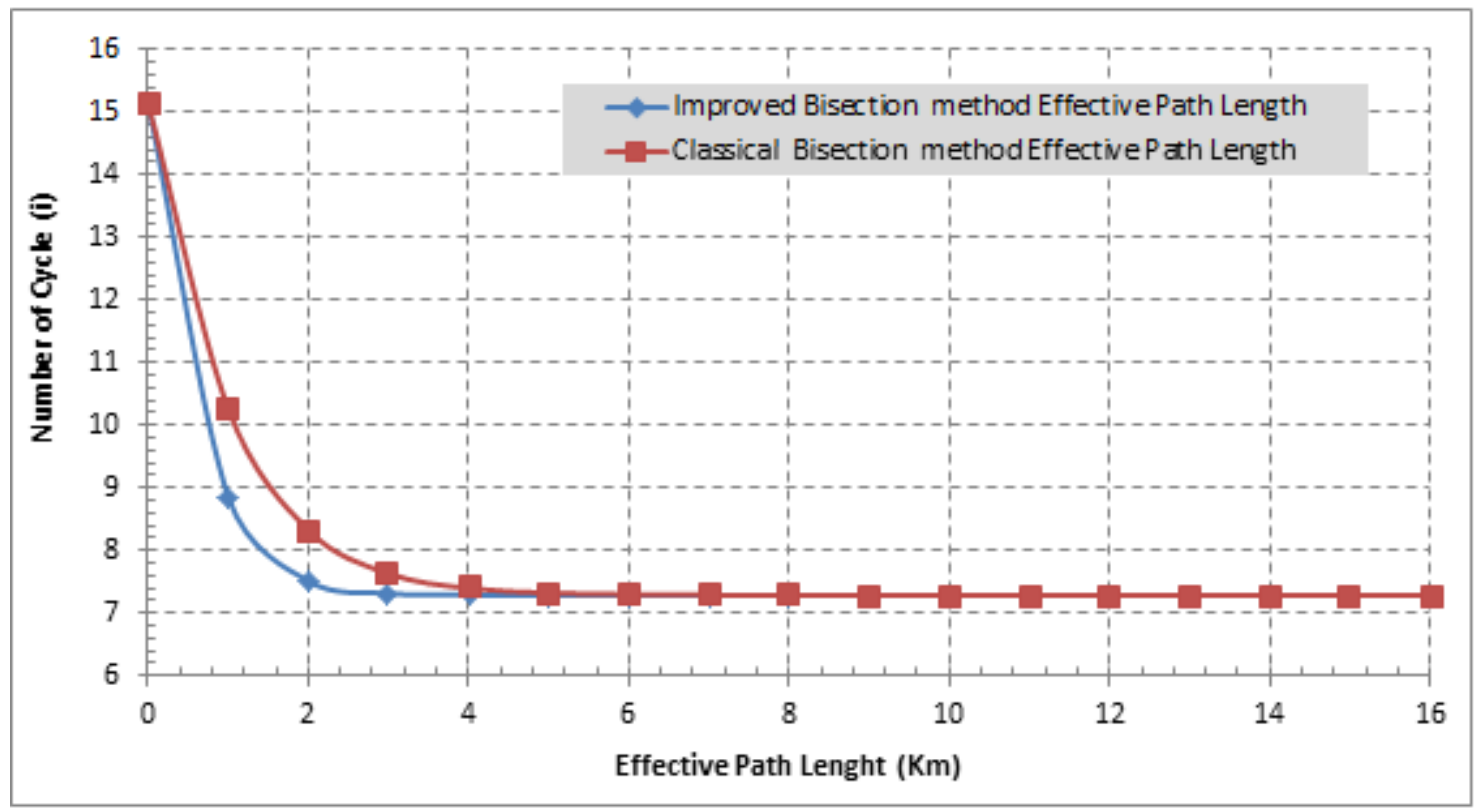

Figure 3. Improved bisection method and the classical bisection method: effective path length versus number of iterations (n)

Table 4. Improved bisection method: effect of frequency on optimal path length, initial path length and convergence cycle

\begin{tabular}{|c|c|c|c|}
\hline $\mathbf{f}(\mathbf{G H z})$ & Convergence Cycle & Initial Path Length $\mathbf{( k m )}$ & Optimal Path Length (km) \\
\hline 10 & 7 & 15.14 & 7.28 \\
\hline 20 & 5 & 7.57 & 2.47 \\
\hline 30 & 5 & 5.05 & 1.48 \\
\hline 40 & 5 & 3.78 & 1.13 \\
\hline 50 & 5 & 3.03 & 0.97 \\
\hline 60 & 4 & 2.52 & 0.89 \\
\hline 70 & 5 & 2.16 & 0.83 \\
\hline 80 & 5 & 1.89 & 0.79 \\
\hline 90 & 6 & 1.68 & 0.76 \\
\hline 100 & 7 & 1.51 & 0.74 \\
\hline 150 & 8 & 1.01 & 0.08 \\
\hline 200 & 8 & 0.76 & 0.05 \\
\hline
\end{tabular}

Effect of Frequency: Table 4, Table 5 and Table 6 (as well as, Figure 4 to Figure 5) show how the various link parameters vary with frequency, from frequency of $10 \mathrm{GHz}$ to $200 \mathrm{GHz}$. Specifically, in Table 4 and Figure 4 the convergence cycle for the improved bisection algorithm varied from 4 to 8 cycles as the frequency is varied from 10 $\mathrm{GHz}$ to $200 \mathrm{GHz}$. On the other hand, the optimal path length decreases from $15.14 \mathrm{~km}$ at $10 \mathrm{GHz}$ to $0.76 \mathrm{~km}$ at 200 GHz. Similarly, in Table 5 and Figure 5, the optimal fade depth and optimal path loss decreased from $24.31 \mathrm{~dB}$ and $129.69 \mathrm{~dB}$ at $10 \mathrm{GHz}$ to $40.77 \mathrm{~dB}$ and $113.23 \mathrm{~dB}$ at 200 $\mathrm{GHz}$ respectively.

The result on convergence cycle versus frequency for the improved bisection method and the classical bisection method are shown in Table 5, Table 6 and Figure 5. As shown in Table 6 , at $10 \mathrm{GHz}$, there is at least over $41 \%$ reduction in the convergence cycle when the improved bisection method is used. However, the study in [27] recorded a convergence cycle of 4 at $12 \mathrm{GHz}$ for the Newton-Raphson method. Essentially, the Newton-Raphson method converges faster than the bisection and the improved bisection method but it is difficult to apply the Newton-Raphson method in most cases where several path losses are to be considered and hence complex mathematical expression need to be formulated along with the derivative of the mathematical expression. On the other hand, the improved bisection method can easily be applied without requiring such complex mathematical expression and it has convergence cycle that is comparable to that of the classical Newton-Raphson method. 
Table 5. Improved bisection method: optimal path length, optimal fade depth, optimal path loss and convergence cycle versus frequency

\begin{tabular}{|c|c|c|c|c|}
\hline $\mathbf{f}(\mathbf{G H z})$ & Convergence Cycle & Optimal Path Length & Optimal Fade Depth & Optimal Path loss \\
\hline 10 & 7 & 7.28 & 24.31 & 129.69 \\
\hline 20 & 5 & 2.47 & 27.69 & 126.31 \\
\hline 30 & 5 & 1.48 & 28.64 & 125.36 \\
\hline 40 & 5 & 1.13 & 28.48 & 125.52 \\
\hline 50 & 5 & 0.97 & 27.81 & 126.19 \\
\hline 60 & 4 & 0.89 & 27.01 & 126.99 \\
\hline 70 & 5 & 0.83 & 26.23 & 127.77 \\
\hline 80 & 5 & 0.79 & 25.50 & 128.50 \\
\hline 90 & 6 & 0.76 & 24.83 & 129.17 \\
\hline 100 & 7 & 0.74 & 24.22 & 129.78 \\
\hline 150 & 8 & 0.08 & 39.54 & 114.46 \\
\hline 200 & 8 & 0.05 & 40.77 & 113.23 \\
\hline
\end{tabular}

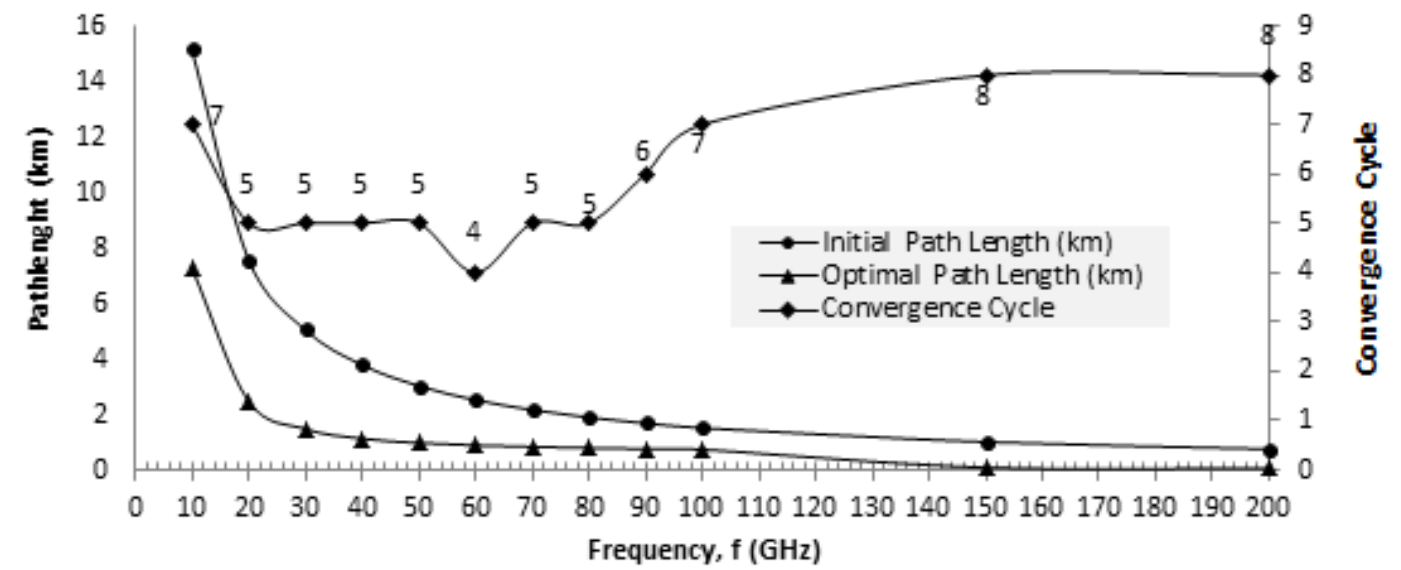

Figure 4. Improved bisection method: effect of frequency on optimal path length, initial path length and convergence cycle

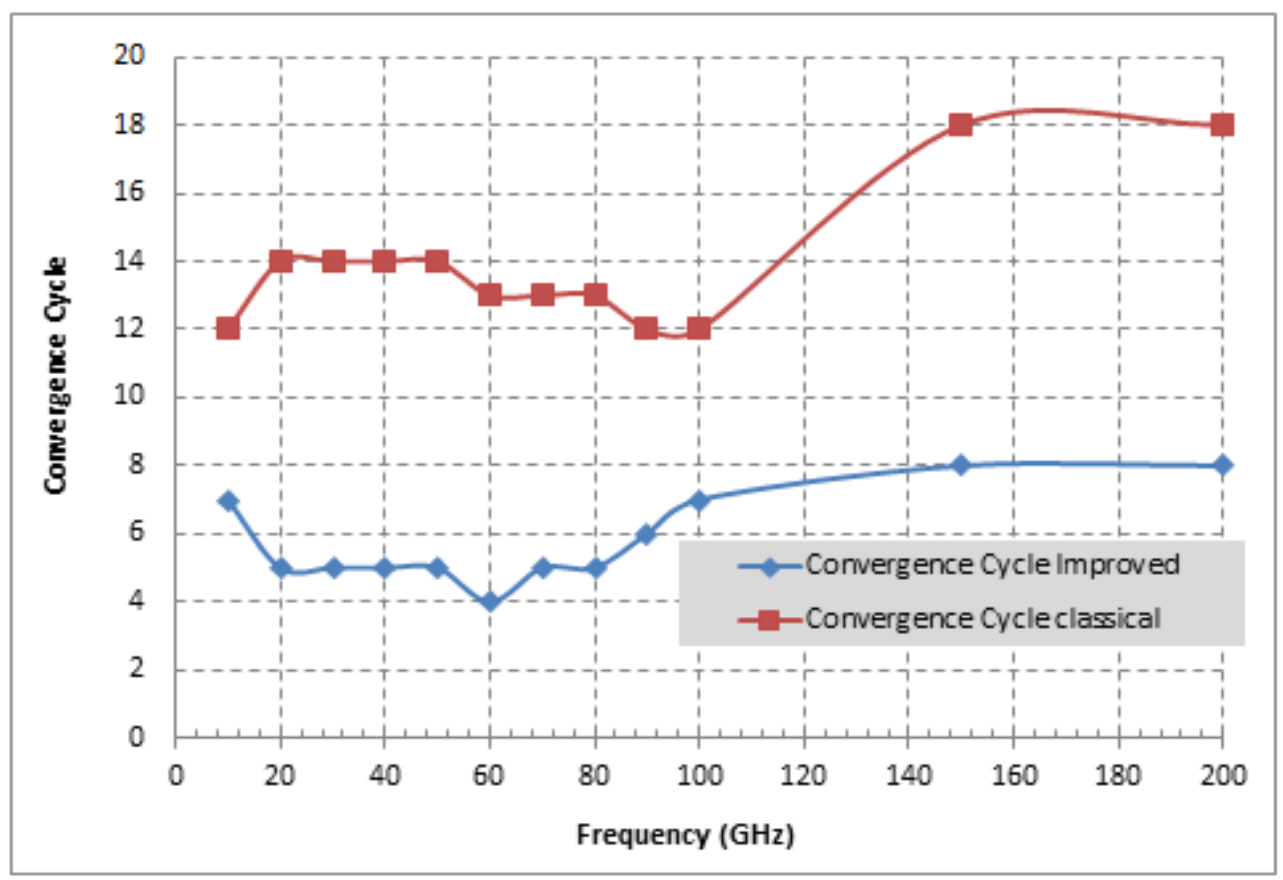

Figure 5. Improved bisection method and the classical bisection method: convergence cycle versus frequency 
Table 6. Improved bisection method and the classical bisection method: convergence cycle versus frequency

\begin{tabular}{|c|c|c|c|}
\hline $\begin{array}{c}\mathbf{f} \\
(\mathbf{G H z})\end{array}$ & $\begin{array}{c}\text { Improved Bisection method } \\
\text { Convergence Cycle (n) }\end{array}$ & $\begin{array}{c}\text { Classical Bisection Method } \\
\text { Convergence Cycle (n) }\end{array}$ & $\begin{array}{c}\text { Percentage Reduction in } \\
\text { Convergence Cycle (\%) }\end{array}$ \\
\hline 10 & 7 & 12 & 41.7 \\
\hline 20 & 5 & 14 & 64.3 \\
\hline 30 & 5 & 14 & 64.3 \\
\hline 40 & 5 & 14 & 64.3 \\
\hline 50 & 5 & 14 & 64.3 \\
\hline 60 & 4 & 13 & 69.2 \\
\hline 70 & 5 & 13 & 61.5 \\
\hline 80 & 5 & 13 & 61.5 \\
\hline 90 & 6 & 12 & 50.0 \\
\hline 100 & 7 & 12 & 41.7 \\
\hline 150 & 8 & 18 & 55.6 \\
\hline 200 & 8 & 18 & 55.6 \\
\hline
\end{tabular}

\section{Conclusions}

An improved bisection algorithm for computing the optimal path length of wireless network link is presented. The performance of the algorithm is expressed in terms of the convergence cycle which is the minimum number of iterations at which the optimal path length is obtained. The performance of the improved bisection algorithm is compared with that of the classical bisection algorithm. In all, significant improvement in convergence cycle is achieved when the improve besection method is used.

\section{REFERENCES}

[1] Hasan, A. (2016). Numerical Study of Some Iterative Methods for Solving Nonlinear Equations. International Journal of Engineering Science Invention, 5(2), 01-10.

[2] Hasan, A., \& Ahmad, N. (2015). COMPARATIVE STUDY OF A NEW ITERATIVE METHOD WITH THAT OF NEWTONS METHOD FOR SOLVING ALGEBRAIC AND TRANSCEDENTAL EQUATIONS.

[3] Khirallah, M. Q., \& Hafiz, M. A. (2013). Solving system of nonlinear equations using family of jarratt methods. International Journal of Differential Equations and Applications, 12(2).

[4] Remani, C. (2012). Numerical methods for solving systems of nonlinear equations. Lakehead University, Thunder Bay, Ontario, Canada, 13.

[5] Suleiman, S. T. M. (2009). Solving System of Nonlinear Equations Using Methods in the Halley Class (Master's thesis, The University of Bergen).

[6] Lally, C. H. (2015). A faster, high precision algorithm for calculating symmetric and asymmetric \$ M $\{\mathrm{T} 2\}$. arXiv preprint arXiv:1509.01831.

[7] Ehiwario, J. C., \& Aghamie, S. O. (2014). Comparative Study of Bisection, Newton-Raphson and Secant Methods of Root-Finding Problems. IOSR Journal of Engineering (IOSRJEN), 4(04).

[8] Ait-Aoudia, S., \& Mana, I. (2004). Numerical solving of geometric constraints by bisection: a distributed approach. International Journal of Computing \& Information Sciences, 2(2), 66 .

[9] Baskar, S., \& Ganesh, S. S. (2005). Introduction to Numerical Analysis.

[10] Arsene, C. T. (2017). Operational decision support in the presence of uncertainties. arXiv preprint arXiv: 1701.04681.

[11] Goodwin, D. L., \& Kuprov, I. (2016). Modified Newton-Raphson GRAPE methods for optimal control of spin systems. The Journal of chemical physics, 144(20), 204107.

[12] Mansouri, P., Asady, B., \& Gupta, N. (2011). A novel iteration method for solve hard problems (nonlinear equations) with artificial bee colony algorithm. World Academy of Science, Engineering and Technology, 59, 594-596.

[13] Figueiredo, J. R., Santos, R. G., Favaro, C., Silva, A. F. S., \& Sbravati, A. (2002). Substitution-Newton-Raphson method applied to the modeling of a vapour compression refrigeration system using different representations of the thermodynamic properties of R-134a. Journal of the Brazilian Society of Mechanical Sciences, 24(3), 158-168.

[14] Intep, S. (2018). A Review of Bracketing Methods for Finding Zeros of Nonlinear Functions. Applied Mathematical Sciences, 12(3), 137-146.

[15] Kobel, A., Rouillier, F., \& Sagraloff, M. (2016, July). Computing Real Roots of Real Polynomials... and now for real! In Proceedings of the ACM on International Symposium on Symbolic and Algebraic Computation (pp. 303-310). ACM.

[16] Bachrathy, D., \& Stépán, G. (2012). Bisection method in higher dimensions and the efficiency number. Periodica Polytechnica Mechanical Engineering, 56(2), 81-86.

[17] Süli, E. (2010). Numerical solution of ordinary differential 
equations. Mathematical Institute, University of Oxford.

[18] Plagianakos, V. P., \& Vrahatis, M. N. (2002). A Derivative Free Minimization Method for Noisy Functions. In Combinatorial and Global Optimization (pp. 283-296).

[19] Tanakan, S. (2013). A new algorithm of modified bisection method for nonlinear equation. Applied Mathematical Sciences, 7(123), 6107-6114.

[20] Kestwal, M. C., Joshi, S., \& Garia, L. S. (2014). Prediction of rain attenuation and impact of rain in wave propagation at microwave frequency for tropical region (Uttarakhand, India). International Journal of Microwave Science and Technology, 2014.

[21] Sarkar, S. K., \& Kumar, A. (2007). Recent studies on cloud and precipitation phenomena for propagation characteristics over India. 92. 60. Nv; 84.40.-x.

[22] Ojo, J. S., Ajewole, M. O., \& Sarkar, S. K. (2008). Rain rate and rain attenuation prediction for satellite communication in $\mathrm{Ku}$ and $\mathrm{Ka}$ bands over Nigeria. Progress in Electromagnetics Research, 5, 207-223.

[23] Kestwal, M. C., Joshi, S., \& Garia, L. S. (2014). Prediction of rain attenuation and impact of rain in wave propagation at microwave frequency for tropical region (Uttarakhand, India). International Journal of Microwave Science and Technology, 2014.

[24] Zheng, L., Lu, N., \& Cai, L. (2013). Reliable Wireless Communication Networks for Demand Response Control. IEEE Trans. Smart Grid, 4(1), 133-140.

[25] Zekavat, P. R., Moon, S., \& Bernold, L. E. (2014). Performance of short and long range wireless communication technologies in construction. Automation in Construction, 47, 50-61.

[26] Xing, G., Lu, C., Zhang, Y., Huang, Q., \& Pless, R. (2007). Minimum power configuration for wireless communication in sensor networks. ACM Transactions on Sensor Networks (TOSN), 3(2), 11.

[27] Emenyi M., Udofia K. M. \& Amaefule O. C., (2017). Computation of Optimal Path Length for Terrestrial Line-of-sight Microwave links Using Newton-Raphson Algorithm. Software Engineering Volume 5, Issue 3, May 2017, Pages: 44-50

[28] Thorvaldsen, P., \& Henne, I. (2014). Propagation measurements on a line-of-sight over-water radio link in Norway. Radio Science, 49(7), 531-548.

[29] Kestwal, M. C., Joshi, S., \& Garia, L. S. (2014). Prediction of rain attenuation and impact of rain in wave propagation at microwave frequency for tropical region (Uttarakhand, India). International Journal of Microwave Science and Technology, 2014.

[30] Sulochana, Y., Chandrika, P., \& Bhaskara Rao, S. V. (2017). Rainrate and rain attenuation statistics for different homogeneous regions of India. Indian Journal of Radio \& Space Physics (IJRSP), 43(4-5), 303-314.

[31] Bhattacharya, R., Das, R., Guha, R., Barman, S. D., \& Bhattacharya, A. B. (2007). Variability of millimeter wave rain attenuation and rain rate prediction: A survey. 